\section{A simple epidural cannula for the rat}

\author{
W. JOSEPH POTTS and PETER F. EAST \\ G. D. Searle \& Co., Chicago, Illinois 60680
}

A simple epidural cannula for use with small animals is described.

Various means of applying $\mathrm{KCl}$ to elicit spreading cortical depression in rats have been described. Ray and Emley (1964), Bureš, Burešová, \& Fifková (1964), and Rudiger and Fifkovả (1963) simply trephined holes in the skull and placed cotton pledgelets into the openings. Burešova and Nadel (1970) and Burešova and Bureš (1968) described a method utilizing a plastic ring which was sutured to the scalp over a trephined skull hole and closed with a screw. Carlson (1967), Tapp (1962), Freedman (1969), and Carew, Crow, \& Petrinovich (1970) placed polyethylene tubing, flanged on one end, through trephined holes in the skull so that the flange lay between the dura and the skull. Potts and Black (1966) and Reed and Trowill (1969) used polyethylene and plastic cannulae, respectively, which were positioned over trephined holes in the skull and fastened with cranioplast cement and jeweler screws. Most recently, Brittain, Zwemke, \& Bugg (1970) described a surface-mounted aluminum cannula which solved some of the problems associated with previously described techniques.

The cannula described here is simple yet rugged and is quickly and easily constructed and implanted. It offers even more advantages than the cannula of Brittain et al (1970). The cannula was constructed by drilling $a$ 1/32-in.-diam hole through the center of a nylon machine screw, Size $4-40 \times 3 / 8$ in., with a binding head (Small Parts, Inc., Miami, Florida). The hole was then enlarged to 3/64 in. diam at the head end to facilitate threading with a 0-80 tap to a depth of $1 / 8$ in. Finally, the base of each screw was smoothed by light grinding or filing, and a $0-80 \times 1 / 8$ in. stainless steel screw was inserted into the threaded head. The completed cannulae, each of which weighed approximately $.14 \mathrm{~g}$, were cleaned and stored in $70 \%$ ethanol until used.

For bilateral implantation of cannulae, rats (180-300 g) were anesthetized $(50 \mathrm{mg} / \mathrm{kg}, \quad$ sodium pentobarbital, IP) and placed into a stereotaxic instrument. A midline incision of the scalp was made, and the skull exposed and dried. A Size $0-80 \times 1 / 8$ in. stainless steel screw was inserted into a small hole drilled, with a No. 2 round dental burr, $2 \mathrm{~mm}$ anterior to the bregma and $2 \mathrm{mr}$ lateral to the sagittal suture. For the cannulae, bilateral holes were drilled, with a No. 8 round dental burr, approximately $3 \mathrm{~mm}$ posterior to the bregma and $3 \mathrm{~mm}$ lateral to the sagittal suture. A cut-off 4-40 stainless steel machine screw held in a pin vise was then turned slowly into each skuil hole to thread them. Each cannula was screwed into the tapped hole for approximately one full turn of the

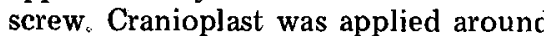
the cannulae and over the stainless steel screw so that good adhesion to the dried skull was obtained. After allowing the cranioplast cement to harden, each cannula was flushed, filled with sterile isotonic saline, and sealed with the $0-80$ stainless steel screw. Finally, the incision was closed with wound clips. Figure 1 shows the completed implant.

In use in this laboratory, these cannulae have proven to be very sturdy and have not been damaged, even when implanted in rats undergoing shuttlebox testing where the cannulae were often bumped quite severely. For other applications it is possible, in the interests of speed and convenience, to eliminate the cranioplast cement and the stainless steel anchor screw. This modification, though weakening the system, has nevertheless shown itself to be useful for short-term applications where there is a minimal risk of physically disturbing the cannula. For smaller animals or other applications where space available on the skull is restricted, it is possible to cut off the screw head, thereby shortening the screw and allowing closer placement of the bilateral cannulae. In this case, the cannulae may be turned into the threaded skull holes using fine pliers or hemostat forceps.

The cannula described by Brittain et al (1970), while eliminating many of the problems associated with previous designs, still is not ideal in several respects. Its size and, presumably, weight prohibit its use in rats smaller than $200 \mathrm{~g}$ and it, too, is dependent on cranioplast alone for its secure attachment to the skull. The cannula described here is smaller and lighter in weight, making possible its use in yet smaller animals. Its screw attachment greatly simplifies the insertion procedure and eliminates the absolute dependence on cranioplast for its adhesion. Leakage between bilateral cannulae, which frequently occurs with surface-mounted types due to seepage under the cranioplast, also is eliminated. This cannula is also

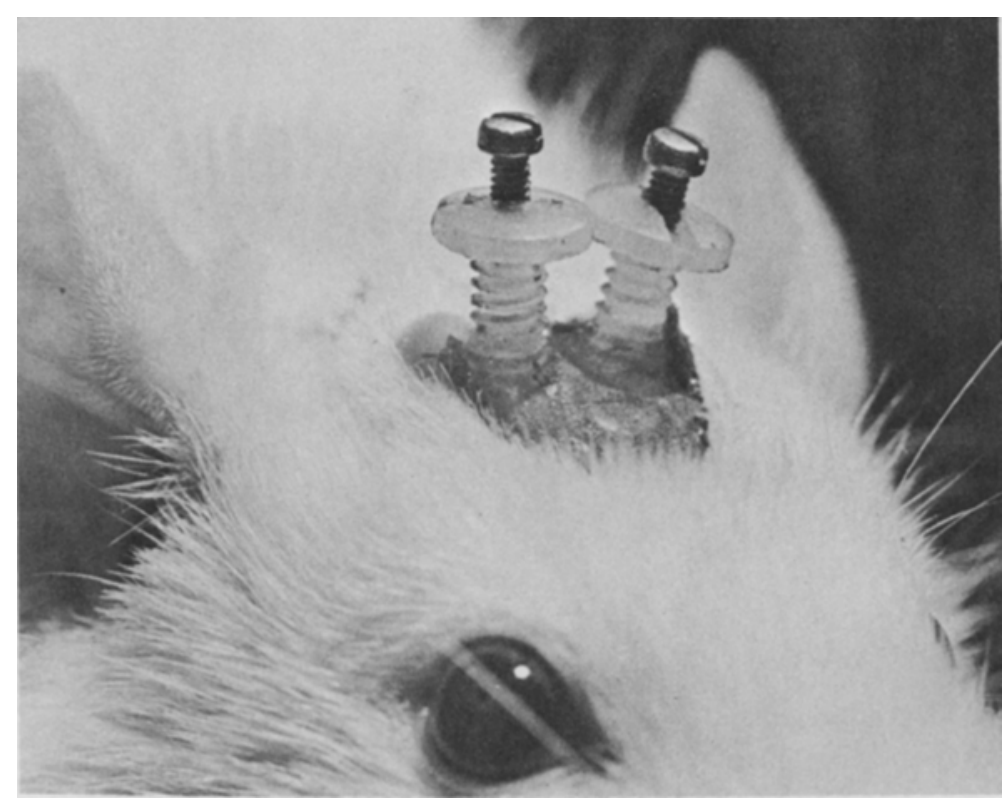


completely sealed, thereby eliminating the need for daily flushing to replace saline lost by spillage or evaporation. Perhaps most important, and in marked contrast to the polyethylene cannula systems mentioned earlier, the cannula described here cannot easily cause a mechanical spreading depression since the rigid fixing practically eliminates any possibility of its movement.

\section{REFERENCES}

BRITTAIN, W. P., ZWEMKE, D. K., \& BUGG, G. L. An inexpensive surface-mounted cannula for the study of spreading depression. Behavior Research Methods \& Instrumentation, 1970, 5, 260-262.

BURES, J., BURESOVA, O. \& FIFKOVÁ,

K. Interhemispheric transfer of a passive avoidance reaction. Journal of Comparative \& Physiological Psychology. $1964,57,326-330$.

BURESOVA, O., \& BUREṠ, J. The role of the transmitting and receiving hemispheres in interhemispheric transfer of T-maze alternation acquired during unilateral spreading depression in rats. Communications in Behavioral Biology Part A, 1968, 1, 115-119.

BURESOVA, O., \& NADEL, L Interhemispheric transfer in the rat. Physiology \& Behavior, 1970, 5, 849-853. CAREW, T. J., CROW, T. J., \& PETRINOVICH, L. F. Lack of coincidence between neural and behavioral manifestations of cortical spreading depression. Science, 1970, 169 1339-1341.

CARLSON, K. Cortical spreading depression and subcortical memory storage. Journal of Comparative \& Physiological Psychology, 1967, 64, 422-430.

FREEDMAN, N. L. Recurrent behavioral recovery during spreading depression.
Journal of Comparative \& Physiological Psychology, 1969, 68, 210-214.

POTTS, W. J., \& BLACK, W. C. The effect of spreading depression on a simple discrimination task. Psychonomic Science, $1966,6,349-350$.

RAY, O. S., \& EMLEY, G. Time factors in interhemispheric transfer of learning. Science, 1964, 144, 76-77.

REED, V. G., \& TROWILL, J, A. Stimulus control value of spreading depression demonstrated without shifting depressed hemispheres. Journal of Comparative \& Physiological Psychology, 1969, 69 40-43.

RUDIGER, W.. \& FIFKOVÁ, E. Operant behavior and subcortical drive during spreading depression. Journal of Comparative \& Physiological Psychology, $1963,56,375-379$.

TAPP, J. T. Reversible cortical depression and avoidance behavior in the rat. Journal of Comparative \& physiological Psychology, 1962, 55, 306-308. 